\title{
Selection of Optimum Reference Frame for the Field Oriented Control of an Induction Motor
}

\author{
Chanchal Singla \\ Electrical and Electronics \\ Engineering Department \\ UIET, Panjab University \\ Chandigarh
}

\author{
Vivek Pahwa \\ Electrical and Electronics \\ Engineering Department \\ UIET, Panjab University \\ Chandigarh
}

\author{
Deepak Kumar \\ Electrical and Electronics \\ Engineering Department \\ UIET, Panjab University \\ Chandigarh
}

\begin{abstract}
In this paper three preferable reference frame used in the simulation of field oriented control of induction machines using $\mathrm{d}, \mathrm{q}$ two axis theory is discussed. Different reference frames are studied as the variables involved are sinusoidal but to design the compensator for control of these variables it is required to convert them in dc variables because it is easy to analyze the linear equations involving these dc variables. This can be done by assuming the reference frame which is revolving at the same speed as that of the sinusoidal variables so that the net relative speed becomes zero and they behave as dc variables. Keeping in view of the above said need the different reference frames for Field Oriented Control of an Induction Motor are studied and analyzed. The whole system is modeled and simulated in MATLAB/Simulink environment.
\end{abstract}

\section{Keywords}

Reference frame, Induction Motor, Field Oriented Control

\section{INTRODUCTION}

Induction motors are asynchronous alternating current motors which are being commonly used these days due to its rugged construction, low cost and reliable operational characteristics. Among these squirrel cage induction motor is the least expensive and most widely used in the industries. These motors are used for medium and high power motor drives because they have higher speeds, higher torques and larger power ratings than $\mathrm{dc}$ motors[1].The most important reason for its growing popularity day by day is its speed control characteristics due to which the $\mathrm{dc}$ motors are being replaced by these motors.

The invention of vector control has brought a drastic change in the field of ac electric drives due to its high static and dynamic performance. This method requires the speed encoder to approximate the rotor speed but the availability of the speed encoder in all industries is major issue so to get rid of the need of speed encoder, synchronous speed and rotor speed can be determined using flux estimator. There are various estimaters available such as Luenberger and Kalman estimators to estimate the flux of the rotor. In this paper the performance of field oriented control of induction motor in various reference frames is studied viz rotor reference frame, stationary reference frame and synchronously rotating reference frame and the waveforms of various currents in all these reference frames have been developed to select the best reference frame for this field oriented control of induction motor.

Various reference frames are discussed below:-

In rotor reference frame

$\omega_{\mathrm{c}}=\omega_{\mathrm{r}}$

Where $\omega_{\mathrm{c}}$ is the angular speed in arbitrary reference frame in $(\mathrm{rad} / \mathrm{sec})$.
This model is useful where the control of switching elements and power are required on rotor side

In stationary reference frame, the speed of the reference frame is that of stator that is 0 ; hence

$\omega_{\mathrm{c}}=0$

This model is useful where real stator variables are required and the rotor variables can be fictitious.

In synchronous reference frame

$\omega_{\mathrm{c}}=\omega_{\mathrm{s}}$

This model is useful for the development of small signal equations where the dc quantities are required in steady state analysis [2] and this frame is mostly used in analog computers because in digital computers the step length required is very large in this frame [3].

Various speed control techniques of induction motor:-

1. Variable Rotor Resistance Control

This method is used only in slip ring motors in which the slip rings can be used to connect the resistances externally in the rotor circuit. During starting the resistances can be connected in circuit and high torque is obtained and whenever the motor picks up the speed the resistances are cut out off the circuit. Most of the $I^{2} R$ losses are dissipated through the resistors. This method is used for high starting torque [4] [5].

\section{Variable Stator Voltage}

The torque developed is proportional to the square of supply voltage provided to its stator terminals. Thus when the supply voltage is varied the torque can also be varied. However this method is used only for small rating cage motors because its control is over a limited range [4].

\section{Scalar Control (constant v/f control)}

This method is based on the principle that to control the speed of the motor the best way is to vary the frequency and the torque is proportional to the ratio of voltage and frequency. So to maintain the voltage to frequency ratio constant to keep the torque constant gives the constant flux. Since the flux is constant full load torque can be maintained constant under steady state condition [6].

But this scheme involves the inherent coupling effect between flux and torque thus this method shows very poor response for transient state however the performance is improved in steady state [7].

\section{Vector Control}

There are two methods of vector control that is direct vector control and indirect vector control [8].In direct vector control the rotor flux is measured directly to determine the transformation angle. However it is physically difficult to determine the rotor 
flux so the estimated value of flux is calculated using stator voltages and currents. Since this value is reliable at low speeds and suffers from the errors from harmonics, so indirect method of vector control is generally preferred [9].

As this technique has similar performance as like separately excited dc motors the vector control is also called decoupling, orthogonal or trans-vector control[10] [11].

\section{MATHEMATICAL MODELLING}

An AC machine is very complex with respect to its construction as the rotor and stator fields are not oriented at 90 degrees but they keep on constantly changing according to its operating conditions. DC machine like performance can be obtained by holding a fixed and orthogonal orientation between the field and armature control in an $\mathrm{AC}$ machine by orienting the stator current with respect to the rotor flux so as to attain independently controlled flux and torque.

Consider the $d-q$ model of induction machine in the reference frame rotating at synchronous speed $\omega_{\mathrm{e}}$.

$V_{q s}=R_{s} i_{q s}+\frac{d}{d t} \psi_{q s}+\omega_{e} \psi d s$

$V_{d s}=R_{s i d s}+\frac{d}{d t} \psi d s-\omega_{e} \psi q s$

$0=R_{s} i_{q r}+\frac{d}{d t} \psi q r+\left(\omega_{e}-\omega_{r}\right) \psi d r$

$0=R_{r} i_{d r}+\frac{d}{d t} \psi d r-\left(\omega_{e}-\omega_{r}\right) \psi_{q r}$

$T_{e}=1.5 \rho \frac{L_{m}}{L_{r}}\left(\psi_{d r} i_{q s}-\psi_{q r} i_{d s}\right)$

Where

$$
\begin{aligned}
& \psi_{q s}=L_{s} i_{q s}+L_{m} i_{q r} \\
& \psi_{d s}=L_{s} i_{d s}+L_{m} i_{d r} \\
& \psi_{q r}=L_{r} i_{q r}+L_{m} i_{q s} \\
& \psi_{d r}=L_{r} i_{d r}+L_{m} i_{d s}
\end{aligned}
$$

The field oriented control implies that the $i_{d s}$ component of stator current would be aligned with the rotor field and the $\mathrm{i}_{\mathrm{qs}}$ component would be perpendicular to $i_{d s}$. This can be accomplished by choosing $\omega_{\mathrm{e}}$ to be the speed of rotor flux and locking the phase of the reference frame system such that the rotor flux is aligned precisely with the d-axis, resulting in

$\psi_{q r}=0 \rightarrow \frac{d}{d t} \psi_{q r}=0$

$\psi d r=\psi r$

Which implies that

$\omega_{s l}=\left(\omega_{e}-\omega_{r}\right)=\left(\frac{L_{m} R_{r}}{\psi_{r} L_{r}}\right) i_{q s}$
And that

$$
T_{e}=1.5 \rho \frac{L_{m}}{L_{r}}\left(\psi_{r} i_{q s}\right)
$$

It also follows that

$$
\frac{d}{d t} \psi_{r}=-\left(\frac{R_{r}}{L_{r}}\right) \psi_{r}+\left(\frac{L_{m} R_{r}}{L_{r}}\right) i_{d s}
$$

The electric torque is proportional to $\mathrm{i}_{\mathrm{qs}}$ component whereas the relation between the flux $\psi_{\mathrm{r}}$ and the $i_{\mathrm{ds}}$ component is given by first order linear transfer function with a time constant $L r / R r$.

\section{RESULTS AND DISCUSSIONS}

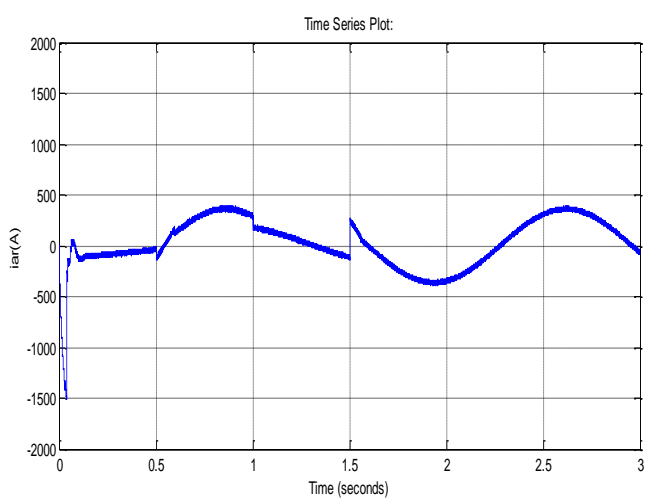

Fig 1(a): Rotor a-axis current in rotor reference frame

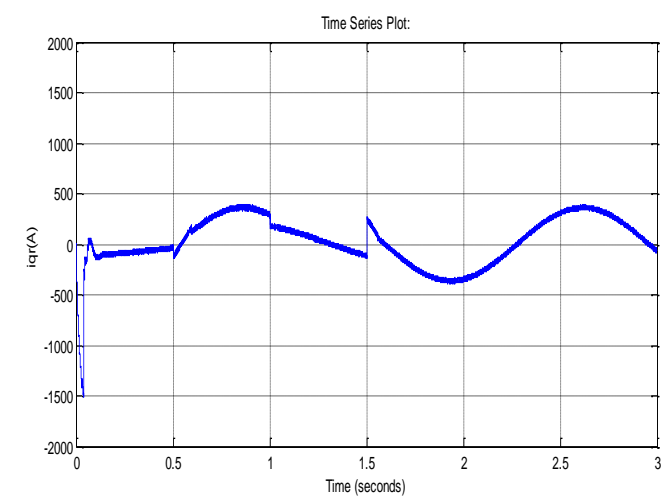

Fig 1(b): Rotor q-axis current in rotor reference frame

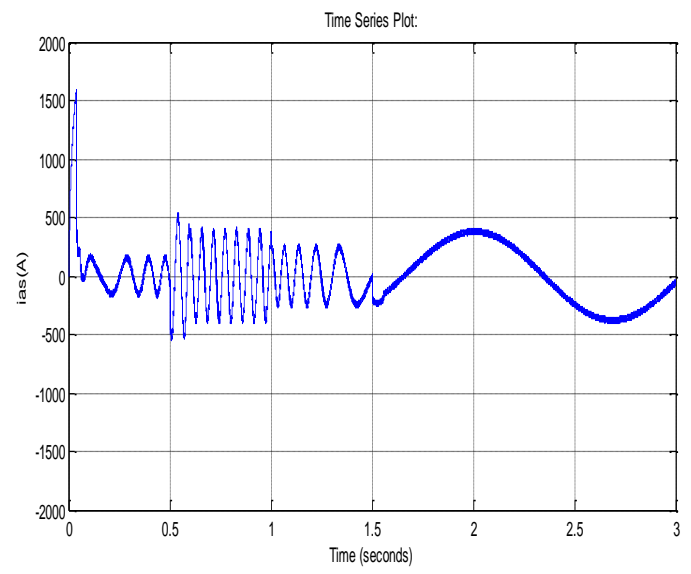

Fig 1(c): Stator a-axis current in rotor reference frame 


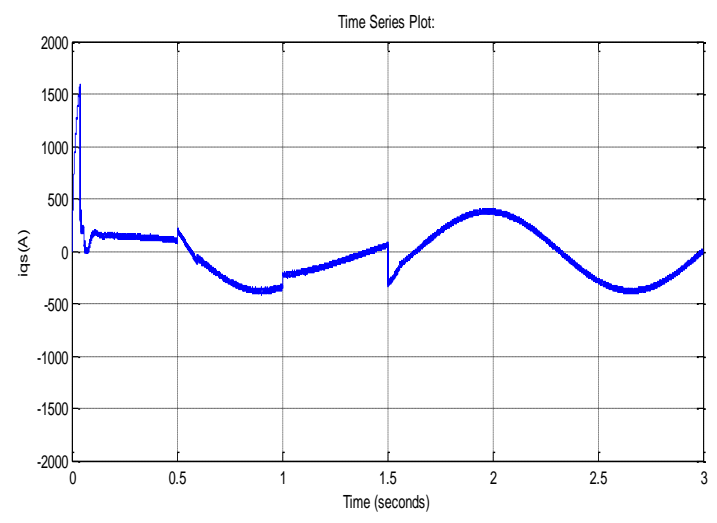

Fig. 1(d). Stator q-axis current in rotor reference frame

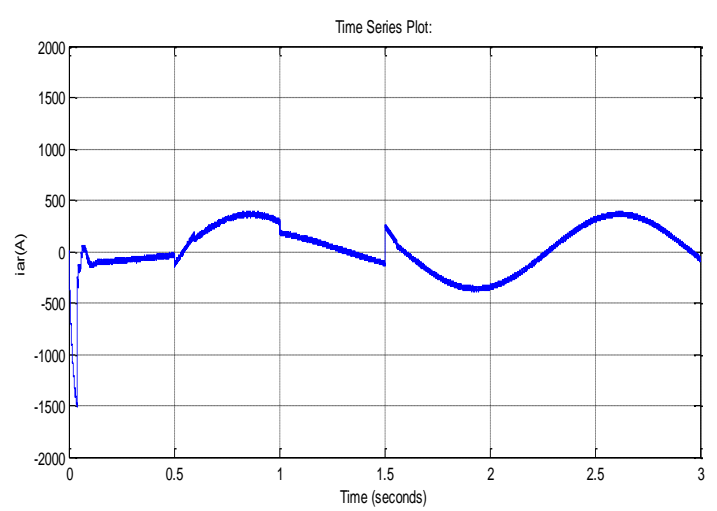

Fig 2(a): Rotor a-axis current in stationary reference frame

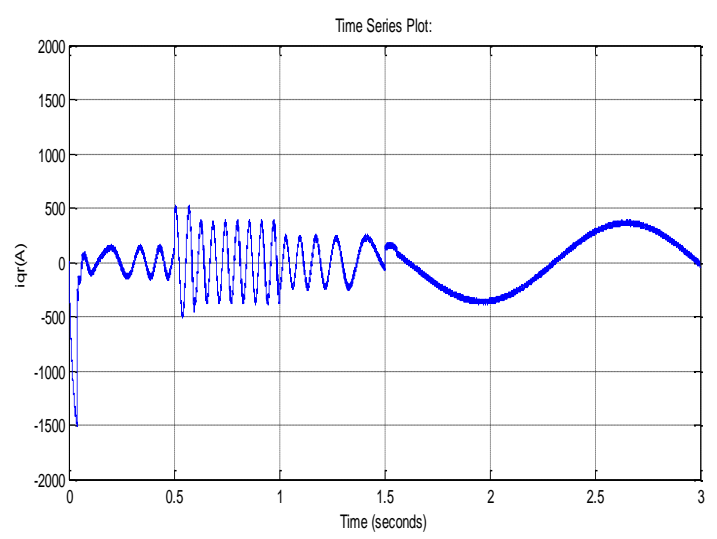

Fig 2(b): Rotor q-axis current in stationary reference frame

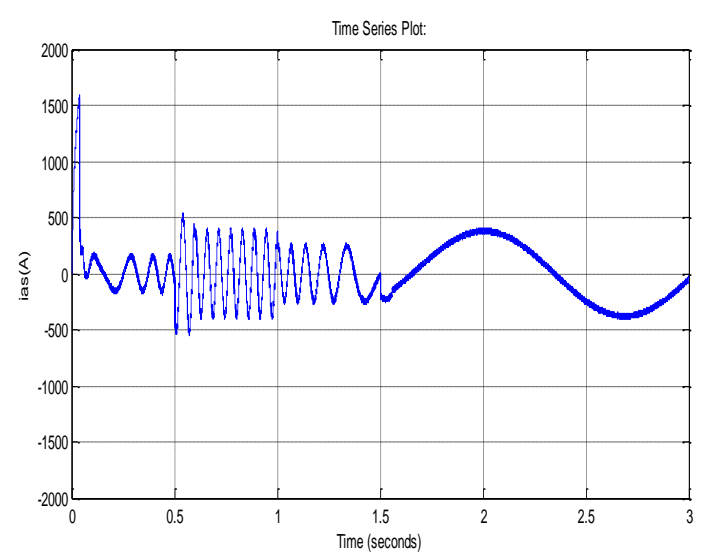

Fig 2(c): Stator a-axis current in stationary reference frame

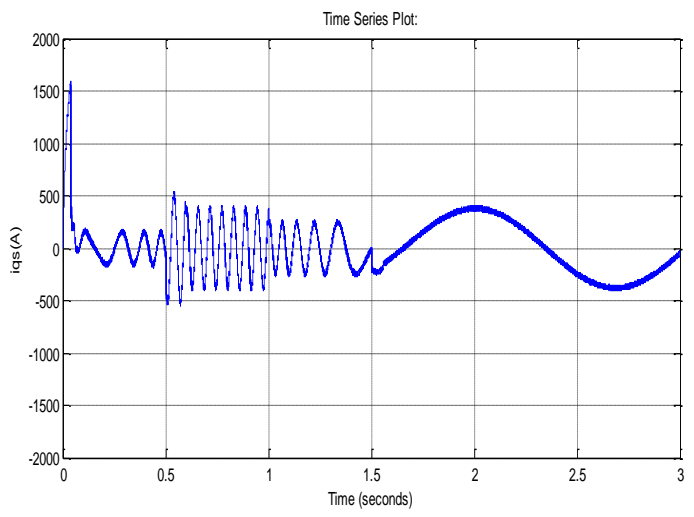

Fig 2(d): Stator q-axis current in stationary reference frame

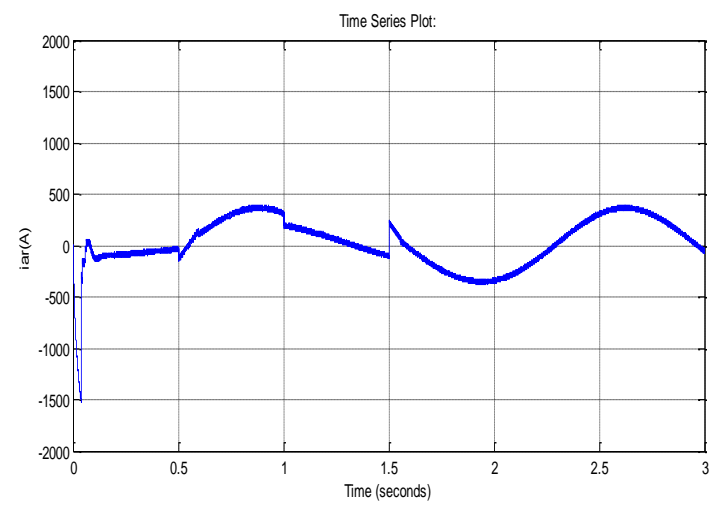

Fig 3(a): Rotor a-axis current in synchronous reference frame

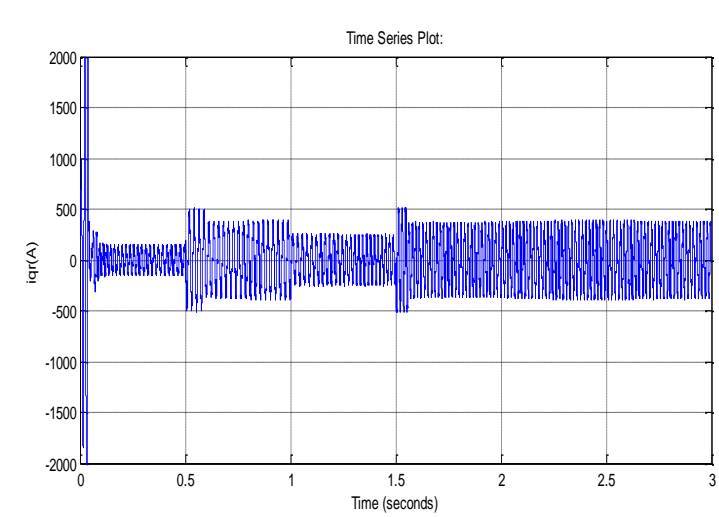

Fig 3(b): Rotor q-axis current in synchronous reference frame

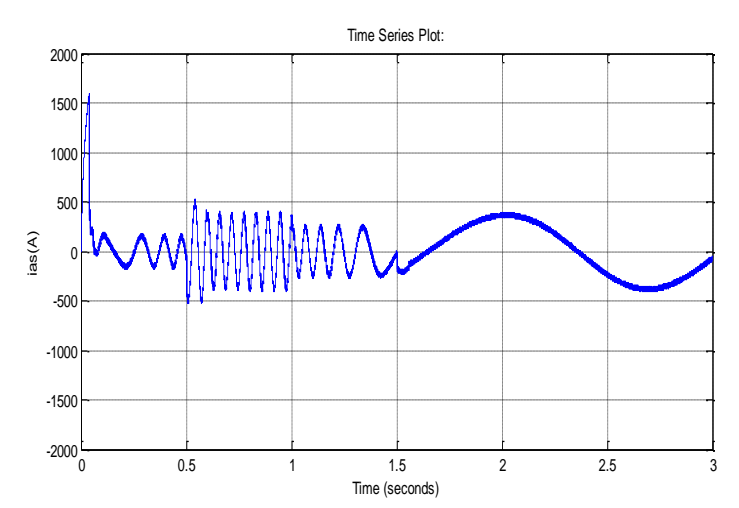

Fig 3(c): Stator a-axis current in synchronous reference frame 


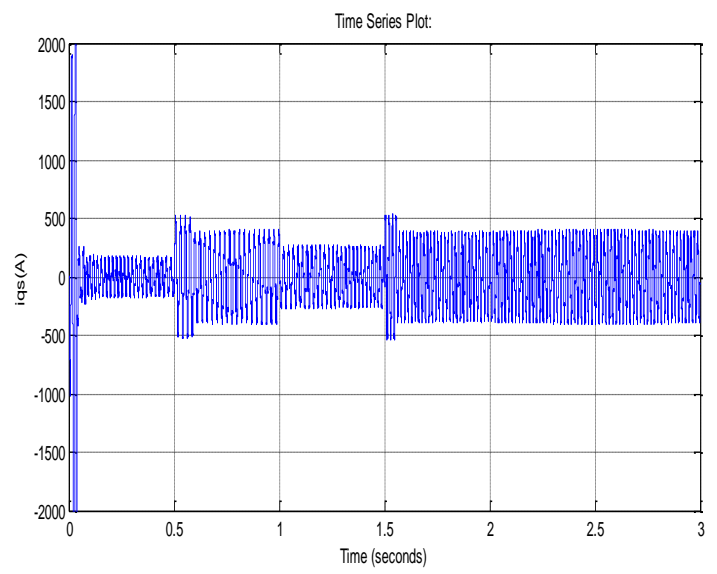

Fig 3(d): Stator q-axis current in synchronous reference frame

\section{CONCLUSION}

Thus the different frames are studied and it is analyzed the following:

1. When the rotor reference frame is used the $q$ axis variables and the rotor phase variables are equal.

2. When the stationary reference frame is used the $q$ axis variables of stator and the stator phase variables are equal.

3. When the synchronous reference frame is used all the currents are of different nature.

Out of the above three reference frames rotor reference frame is best suited for the field oriented control of induction motor. This method is concerned with the phasor control of rotor flux linkages, hence this reference frame is used in this control of induction motor because the selection of reference frame is based on the controlling variables whether the controlling variables are of stator or rotor.

\section{REFERENCES}

[1] Bimal. K. Bose, "Modern Power Electronics and AC Drives," Prentice Hall PTR. Prentice-Hall Inc.Upper Saddle River NJ 07458,2002

[2] R.Krishnan, "Electric motor drives modeling,analysis and control" , Pearson Prentice Hall , 2007.

[3] R.J.LEE, P.PILLAY and R.G.HARLEY, “ D-Q reference frames for the simulation of induction motors" ,Electrical powers systems research, 8(1984/85).

[4] G.K.Dubey, "Fundamental Of Electrical Drives" , Narosa Publication, Second Edition, 2011.
[5] A.S.Zein El-Din, A.E.El-Sabbe, “ A Novel Speed Control Technique For Single -Phase Induction Motor," IEEE International Conference on Power Electronics and Drive Systems, PEDS'99, July 1999, Hong Kong

[6] www.renesas.com

[7] Atul M. Gajare, Nitin R. Bhasme, “ A Review On Speed Control Techniques of Single -Phase Induction Motor", IJCTEE Vol 2, Issue 5, October 2012

[8] B.K.Bose, “ Modern Power Electronics and AC Drives", Pearson Education, $4^{\text {th }}$ Edition , 2004.

[9] Novotny, D.W., Lipo, “ Vector Control and Dynamics of AC Drives”, T.A.1996 Oxford University Press, New York

[10] Khalaf Salloum Gaied , Hew Wooi Ping, Haider A.F.Mohamed "Indirect Vector Control of a Variable Frequency Induction Motor Drive (VCIMD)," ICICI-BME 2009 Proceedings.

[11] G.O.Garcia, R.M.Stephan, E.H. Watanabe, "Comparing the Indirect Field-Oriented Control with a Scalar Method ,'IEEE Trans, Industrial Electronics Vol.41, No. 2, pp 201-207 April 1994.

\section{APPENDIX}

\section{List of Symbols}

$\omega_{\mathrm{r}}=$ angular speed in rotor reference frame

$\omega_{\mathrm{s}}=$ angular speed in synchronous reference frame

$\mathrm{V}_{\mathrm{qs}}=$ stator $\mathrm{q}$ axis voltage

$\mathrm{V}_{\mathrm{ds}}=$ stator $\mathrm{d}$ axis voltage

$\mathrm{Rs}=$ stator resistance

$\mathrm{I}_{\mathrm{qs}}=$ stator $\mathrm{q}$ axis current

$\mathrm{I}_{\mathrm{ds}}=$ stator $\mathrm{d}$ axis current

$\Psi_{\mathrm{qs}}=$ stator $\mathrm{q}$ axis flux linkage

$\Psi_{\mathrm{ds}}=$ stator d axis flux linkage

$\mathrm{I}_{\mathrm{dr}}=$ rotor $\mathrm{d}$ axis current

$\mathrm{I}_{\mathrm{qr}}=$ rotor $\mathrm{q}$ axis current

$\Psi_{\mathrm{qr}}=$ rotor $\mathrm{q}$ axis flux linkage

$\Psi_{\mathrm{dr}}=$ rotor d axis flux linkage

$\mathrm{R}_{\mathrm{r}}=$ rotor resistance

$\mathrm{T}_{\mathrm{e}}=$ Electromagnetic Torque

$\rho=$ Differential Operator

$\mathrm{L}_{\mathrm{m}}=$ mutual inductance

$\mathrm{L}_{\mathrm{r}}=$ rotor inductance 